\title{
A New Quantitative Approach to the Study of Divergence in the Progress of Economies
}

Julian Su Vettoor ( $\square$ jsvettoor@gmail.com )

https://orcid.org/0000-0003-4795-2597

\section{Method Article}

Keywords: Divergence index, Great divergence, Little divergence, Silver wage, GDP per capita

Posted Date: May 21st, 2021

DOl: https://doi.org/10.21203/rs.3.rs-544125/v1

License: (c) (i) This work is licensed under a Creative Commons Attribution 4.0 International License. Read Full License 


\title{
A NEW QUANTITATIVE APPROACH TO THE STUDY OF DIVERGENCE IN THE PROGRESS OF ECONOMIES
}

\author{
Julian Su Vettoor
}

Mailing Address: Julian Su Vettoor, Sumanu, Vettoor House, Ettumanoor, PIN-686631, India jsvettoor@gmail.com

ORCID NUMBER : 0000-0003-4795-2597

\begin{abstract}
A new method is introduced to study divergence between economies. Data indicative of economic progress is utilised for this study. The data for a less developed economy is expressed as a percentage of a more developed economy for the corresponding years. Then a correlation between the newly generated values with the data for the developed economy is calculated. This is named as divergence index. A negative value close to -1 for this index signifies great divergence and a positive value signifies the absence of divergence. This idea is applied to data for silver wages and GDP (Gross Domestic Product) per capita for Asian and European economies with the British economy as a reference. The divergence index calculated for Asian countries with respect to Britain show that a Great divergence existed for
\end{abstract}


the imperial period. A similar calculation for Italy with Britain reveals the greater extent of divergence than that was often conceived regarding the idea of little divergence.

\section{Keywords}

Divergence index . Great divergence . Little divergence . Silver wage . GDP per capita

\section{Introduction}

In the economic history of the world, during the modern period, there is a so called "great divergence" between the growth patterns of Great Britain and the Asian countries. In this period two significant developments occurred. First was the colonisation of many countries in Asia by the European powers and the second was the industrial revolution that occurred in Europe pioneered by Great Britain.

It is often argued that the colonisation played a major role in bringing about this divergence between the colony and the coloniser. But one can see such a divergence between Great Britain and China which was not directly under any colonial power. This points to the role of industrial revolution and the mercantile capitalism acting as major factors in causing the divergence. The distribution of energy sources and the discovery of the new world was attributed to the reasons for the divergence. The sustained industrial development occurred only in western Europe which might have been a result of this divergence itself. (Pomeranz, Kenneth 2000) While Kenneth addresses the issue in the context of China with respect to Western Europe, this study intends to shed light on the conditions of Asian countries like India and Indonesia as well. The study focuses on the pattern of economic development which evolved during the renaissance period, the industrial revolution period, and the era of imperialism. Even though, many west European countries developed at a fast pace, Britain pioneered the industrial revolution. The Portuguese, the French and the Dutch recorded early 
success in the maritime trade with the east. Though Britain arrived late on the western coasts of the east, they possessed several superior aspects which aided them to oust their predecessors from the vibrant markets.

The notion of "the great divergence" signifies the accelerated growth of European economies and the sluggish growth of the Asian economies. In this work, a new quantitative approach is suggested to characterize the divergence in the economies. The most debated issue of whether the colonies grew with their imperial country is analysed using the quantitative technique of correlation. This can provide a more rigorous understanding of the divergence of the economies.

What puzzles a historian is why the scientific revolution and the consequent industrial revolution happened only in the European countries. These European countries had a profound role in the progress or decline of the economies across the world. The markets across the globe responded to these changes in varied ways and strengths. The evolution of the economies like that of India, China and Indonesia were mostly rated as declining, while the European colonial powers flourished. The debate on "the great divergence" brings us to the scrutiny of both the colonies and their colonisers.

The indices of human development are often the tools for the measurement of any society or economy, in the modern perspective. The analysis would require reliable information and data sources of the period under study. This becomes more and more difficult as the period of study goes deeper into the past, which urges the economic historian to get hold of those data sources which when computed and compiled would aid a comparative quantitative study.

\section{Methodology}


The values of the relevant quantities for characterising the economies are utilised for finding the divergence. Let the quantity for the dominant economy be represented by " $x$ " variable and that for the other economy by " $y$ " variable. The formula for correlation is arrived after the calculation of the standard deviation. The standard deviation for the $x$ variable $\left(S_{x}\right)$ and that for the $y$ variable $\left(S_{y}\right)$ is calculated. (Hudson Pat, 2000)

Correlation $r$ is given by the formula

$$
r_{x y}=\frac{\operatorname{cov}(x y)}{S_{x} S_{y}}
$$

$\operatorname{COV}(x y)$ is the covariance of $x$ and $y$

$S_{x}$ and $S_{y}$ are the standard deviations of $x$ and $y$ variables respectively

$$
\text { Where } \operatorname{COV}(x y)=\frac{\sum_{i=1}^{i=n}\left(x_{i}-\bar{x}\right)\left(y_{i}-\bar{y}\right)}{n}
$$

Where $\bar{x}$ and $\bar{y}$ are the mean values of $x$ and $y$ variables respectively $n$ is the no pairs of data used to study the correlation.

$$
\begin{gathered}
S_{x}=\sqrt{\frac{\sum_{i=1}^{i=n}\left(x_{i}-\bar{x}\right)^{2}}{n}} \\
S_{y}=\sqrt{\frac{\sum_{i=1}^{i=n}\left(y_{i}-\bar{y}\right)^{2}}{n}}
\end{gathered}
$$

The correlation coefficient can be calculated using equation no. 1. Suppose for the two sets of values, if both are increasing, correlation will be positive. The coefficient cannot distinguish between a non divergent situation from a divergent situation. By a divergent situation we mean that the second set of values expressed as a percentage of the first set is decreasing. This can happen in two situations. 1) When the first set is increasing and the second set is decreasing. 2) The first set is increasing, the second set is also increasing but at a slow rate. When we choose the variables, the set with higher values (the variable belonging to the dominant economy) has to be taken as the $x$ variable. For the other variable (y) a new variable is defined $(z)$ in terms of $x$. 
$z_{i}=\frac{y_{i}}{x_{i}} \times 100$

A correlation coefficient between the $x$ variable and the $z$ variable is calculated. This correlation coefficient $\left(r_{x z}\right)$ can characterize the divergence between the two sets of values $(x, y)$. So it can be called a divergence index $(D)$.

$D=r_{x z}=\frac{\sum_{1}^{n}\left(x_{i}-\bar{x}\right)\left(z_{i}-\bar{z}\right)}{\sqrt{\sum_{1}^{n}\left(x_{i}-\bar{x}\right)^{2}} \sqrt{\sum_{1}^{n}\left(z_{i}-\bar{z}\right)^{2}}}$

Where $n$ is the no of values in each set and

$$
\bar{z}=\frac{1}{n} \sum_{i=1}^{i=n} z_{i}
$$

To show how this method can be applied is illustrated through fictitious set of values as given in tables 1 and 2 .

In this case, the $y$ values are also increasing, but at a slow rate. So the $y$ values as a percentage of $x$ shows a general decreasing trend even though there is a fluctuation. On the whole the analysis shows a negative correlation $\left(r_{x z}\right)$ signifying a divergence. The method is a powerful tool to clearly bring out whether there is an overall divergence, even in cases with great fluctuations in the data.

In the case 2 , the second set of values $(y)$ is also increasing. But their increase is significant with respect to the first set of values $(x)$, and a negative correlation is not obtained signifying the absence of a divergence. (Table 2)

In cases where there are fluctuations it is not possible to arrive at a conclusion regarding the divergence merely by calculating the percentage of the second variable with respect to the 
first variable. The method outlined here can give us information about the overall divergence in a period without ambiguity.

\section{Application of the method to calculate an index for divergence}

The wages of the unskilled and skilled labourers in both England (South England) and India is utilised for the study. ${ }^{1}$ (Table 3). A glance at the figures reveals the divergence in the silver wage in grams per day. There is a slight increase in the silver wage in the case of India, which can put to question the divergence idea. Here a reference to the Indian wage expressed as the percentage of the English wage is made in the data set. The percentage values are found to decrease over the years. There arises the need for a precise and conclusive evaluation of this divergence. The statistical technique suggested in the methodology section is applied to this data.

Applying this method to the economies of Great Britain and India over the period ranging from $1550-1850$, the silver wage data is put to analysis. This brings out conclusive results about the divergence and its magnitude in the case of England and India. (Table 3)

The increase of silver wages for southern England is very large compared to the nominal increase in case of India. A correlation calculated between the two wages, would yield a positive value (0.82182) and hence no conclusive inference about divergence could be achieved. Now the Indian silver wage as a percentage of that of the English silver wage is calculated for each value. The percentage value so obtained will determine the extent of

\footnotetext{
${ }^{1}$ The set of data which gives the approximate wages of the unskilled labourers in England and India for the same period (starting from 1550 to 1849) is taken from Broadberry and Gupta (2006).
} 
divergence if any. When the divergence index is calculated using the aforesaid method (presented in methodology), a negative correlation of -0.825167 is obtained. This value signifies a clear divergence between the English and Indian silver wages and hence a great divergence between the two economies.

\section{The Great and Little Divergence}

The shift in the levels of prosperity within European countries from the period 1400 to 1800 is often referred to as the little divergence. Great Britain and Netherlands surpassed the Italian and Spanish hegemony in the economic progress. This gap is evident from the maritime trade and the consequent colonisation. The success in colonising is bound to have opened up tremendous opportunities to the coloniser compared to those countries which could not find colonies. These differences in availability and the capability to appropriate resources had greater significance with the onset of industrial revolution. The data related to the economic advancements of various European countries, compiled by the Angus Maddison (Maddison, A. 2001) is utilised here. The estimates of GDP (Gross Domestic Product) per capita for the European countries in the period 1500 to 1950 is considered for the analysis of divergence. The data for England and Italy is tabulated as per Maddison's estimate in table (4).

The divergence index calculated yields a negative value (-0.679) which is indicative of a significant divergence. This analysis can be carried out using GDP per capita for the Asian economies like China, India and Indonesia with respect to that of England. (Tables 5,6 and 7)

The values of divergence index for China, India and Indonesia with respect to England are found to be $-0.863,-0.838$ and -0.839 respectively. The values close to -1 indicates the greater scale of divergence between the respective economies and England. The value of the 
index for Italy and England is found to be -0.679 which is slightly less divergent than the Asian economies.

\section{Conclusion}

The above analysis shows the power of the method suggested for finding the divergence between economies. In cases where there are fluctuations in the data, a percentage calculation alone will not provide conclusive information regarding the existence of divergence over a certain period. But the method suggested here is capable of giving a consolidated information regarding divergence between economies. This study illustrates the existence of divergence between England and the Asian economies during the period $1500-1950 \mathrm{CE}$. For this analysis, the silver wage per capita (Southern England and India) and the GDP per capita (England and Asian economies) are employed. Both calculations show the existence of divergence between these economies. The calculation of divergence index for Great Britain and Italy using GDP per capita shows a significant divergence with a value of -0.678 . But this analysis shows that the so called little divergence was not as little as it is generally held.

\section{References}

Broadberry, SN and B Gupta (2006) The Early Modern Great Divergence: Wages, Prices and Economic Development in Europe and Asia, 1500-1800. Economic History Review 59: 2-31.

Maddison A (2001) The World Economy: A Millennial Perspective. Paris: OECD. 2003a. The World Economy: Historical Statistics. Paris: OECD.

Hudson Pat (2000) History by numbers. New York : Oxford University Press, Inc. : 147-148. Van Zanden, Jan Luiten (2009) “The Skill Premium and the 'Great Divergence'. "European Review of Economic History 13, no. 1 : 121-53. 
Pomeranz Kenneth (2000) The Great Divergence: China, Europe, and the Making of the Modern World Economy. Princeton: Princeton University Press.

Humphries Jane (2013) "The Lure of Aggregates and the Pitfalls of the Patriarchal Perspective: A Critique of the High Wage Economy Interpretation of the British Industrial Revolution” Economic History Review 66, no. 3 : 693-714.

Allen Robert C (2009) The British Industrial Revolution in a Global Perspective. Cambridge, UK: Cambridge University Press.

Table (1)

Sample data (fictitious) used to analyse the divergence of two variables: Case 1

\begin{tabular}{ccccc}
\hline $\begin{array}{c}\text { Sl no. } \\
i\end{array}$ & Value of $x$ & Value of $y$ & $z=(y / x) \times 100$ & Divergence \\
& variable & variable & & \\
\hline 1 & 5 & 3 & 60 & \\
\hline 2 & 8 & 4 & 50 & \\
\hline 3 & 13 & 6 & 46.15 & \\
\hline 4 & 17 & 8 & 47.05 & \\
\hline 5 & 21 & 9 & 42.85 & \\
\hline 6 & 29 & 11 & 37.93 & \\
\hline 7 & 32 & 15 & 46.87 & \\
\hline
\end{tabular}


Table 2

Sample data (fictitious) used to analyse the divergence of two variables: Case 2

\begin{tabular}{ccccc}
\hline $\begin{array}{c}\text { Sl no. } \\
i\end{array}$ & Value of $x$ & Value of $y=(y / x) \times 100$ & Divergence \\
& variable & variable & & $D=r_{x z}$ \\
\hline 1 & 5 & 4 & 80 & \\
\hline 2 & 8 & 7 & 87.5 & \\
\hline 3 & 13 & 11 & 84.62 & 0.078 \\
\hline 4 & 17 & 14 & 82.35 & \\
\hline 5 & 21 & 18 & 85.71 & \\
\hline 6 & 29 & 22 & 75.86 & \\
\hline 7 & 32 & 29 & 90.62 & \\
\hline
\end{tabular}


Table 3

Silver wage of Southern England and India and the computation of divergence index

\begin{tabular}{|c|c|c|c|c|}
\hline \multirow[t]{5}{*}{ Period } & \multicolumn{2}{|c|}{ Silver wage per day in grams } & \multirow{2}{*}{$\begin{array}{l}\text { Indian silver } \\
\text { wage as a }\end{array}$} & \multirow{2}{*}{$\begin{array}{l}\text { Divergence } \\
\text { Index }\end{array}$} \\
\hline & Southern & India & & \\
\hline & \multirow[t]{3}{*}{ England } & & Percentage of that & \multirow[t]{3}{*}{$D$} \\
\hline & & & of southern & \\
\hline & & & England & \\
\hline $1550-99$ & 3.4 & 0.7 & 21 & \multirow{5}{*}{-0.825} \\
\hline $1600-49$ & 4.1 & 1.1 & 27 & \\
\hline $1650-99$ & 5.6 & 1.4 & 25 & \\
\hline $1700-49$ & 7.0 & 1.5 & 21 & \\
\hline $1750-99$ & 8.3 & 1.2 & 14 & \\
\hline
\end{tabular}


Source: Broadberry and Gupta (2006)

Table (4)

GDP per capita of Britain and Italy compared using Divergence index

\begin{tabular}{lllll}
\hline Year & GDP per & GDP per & Italian GDP per capita as a & Divergence index \\
& capita of & capita of & percentage of that of & $D$ \\
& Britain (1990 & Italy & Britain (\%) & \\
& USD) & $(1990$ USD) & & \\
\hline 1500 & 762 & 1100 & 144.35 & \multirow{2}{*}{0.679} \\
\hline 1700 & 1405 & 1100 & 78.29 & \\
\hline 1820 & 2121 & 1117 & 52.66 & \\
\hline 1913 & 5150 & 2564 & 49.78 & \\
\hline 1950 & 6907 & 3502 & 50.70 & \\
\hline
\end{tabular}


Note: The GDP per capita values are expressed in international dollars with the base year as 1990.

Source: Maddison, A. 2001. The World Economy: A Millennial Perspective. Table 2 - 22a.

Table (5)

GDP per capita of Britain and China to compute the divergence index

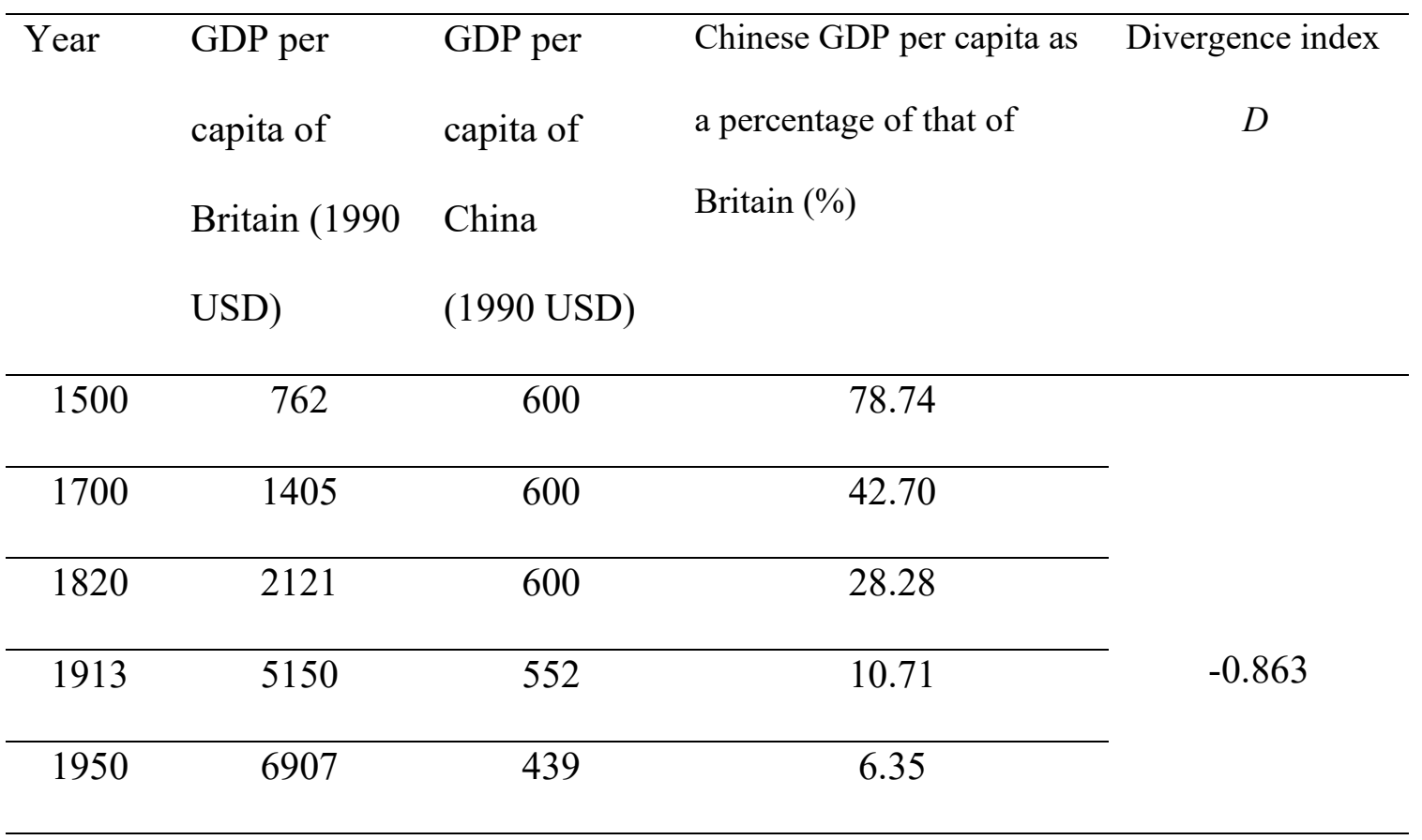


Note: The GDP per capita values are expressed in international dollars with the base year as 1990.

Source: Maddison, A. 2001. The World Economy: A Millennial Perspective. Table 2 - 22a.

Table (6)

GDP per capita of Britain and India to compute the divergence index

\begin{tabular}{|c|c|c|c|c|}
\hline \multirow[t]{3}{*}{ Year } & $\begin{array}{l}\text { GDP per } \\
\text { capita of }\end{array}$ & $\begin{array}{l}\text { GDP per } \\
\text { capita of }\end{array}$ & $\begin{array}{l}\text { Indian GDP per capita as a } \\
\text { percentage of that of }\end{array}$ & $\begin{array}{c}\text { Divergence index } \\
D\end{array}$ \\
\hline & Britain (1990 & India & Britain (\%) & \\
\hline & USD) & (1990 USD) & & \\
\hline 1500 & 762 & 550 & 72.17 & \\
\hline 1700 & 1405 & 550 & 39.14 & \\
\hline 1820 & 2121 & 533 & 25.12 & -0.838 \\
\hline 1913 & 5150 & 673 & 13.06 & \\
\hline 1950 & 6907 & 619 & 8.96 & \\
\hline
\end{tabular}


Note: The GDP per capita values are expressed in international dollars with the base year as 1990.

Source: Maddison, A. 2001. The World Economy: A Millennial Perspective. Table 2 - 22a.

Table (7)

GDP per capita of Britain and Indonesia to compute the divergence index

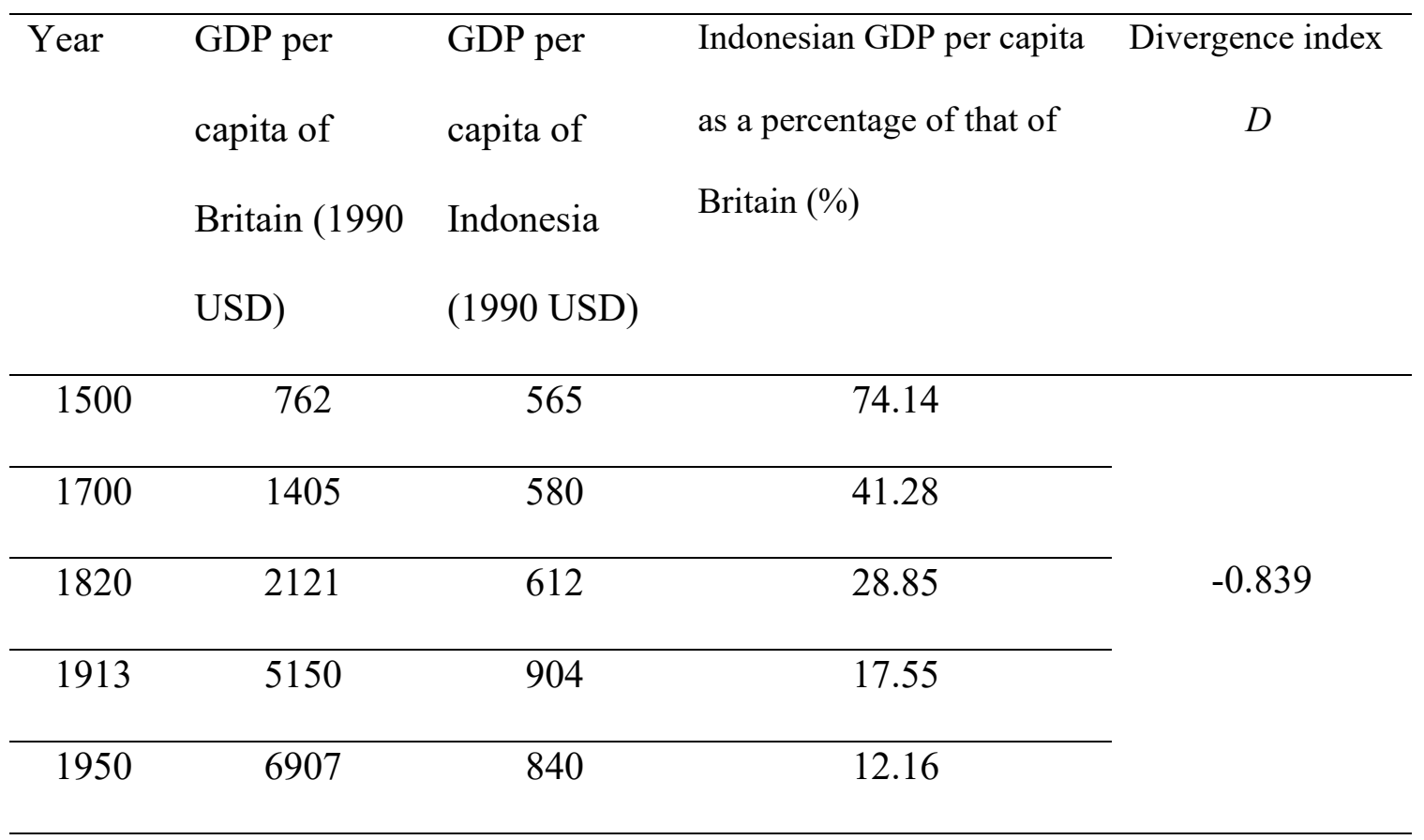


Note: The GDP per capita values are expressed in international dollars with the base year as 1990.

Source: Maddison, A. 2001. The World Economy: A Millennial Perspective. Table 2 - 22a. 